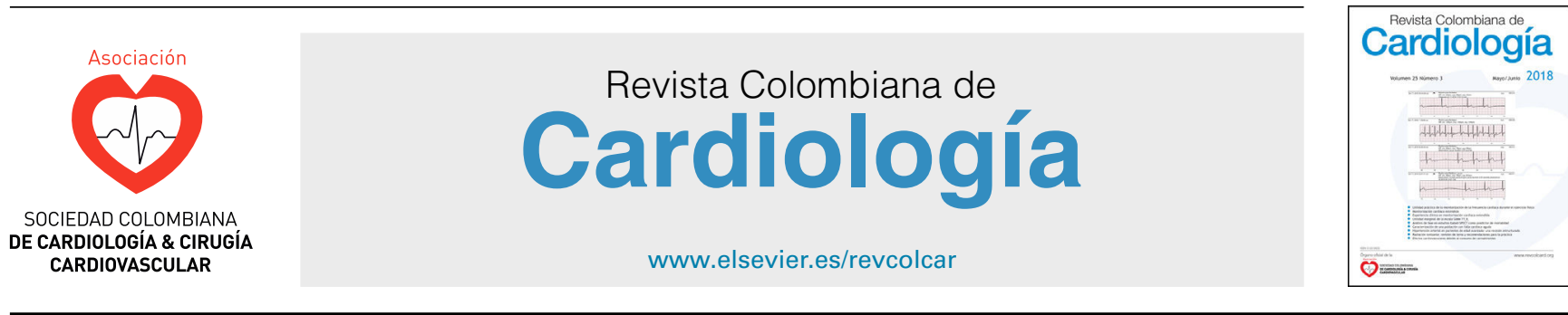

\title{
EDITORIAL
}

\section{Entre guerras y pandemias ¿volveremos a ser los mismos? ¿Hay duda de la resiliencia de la humanidad?}

\section{Between wars and pandemics, will we be the same? Is there any doubt on the resilience of humanity?}

\section{Darío Echeverri}

\author{
Editor en Jefe, Revista Colombiana de Cardiología
}

Recibido el 1 de abril de 2020; aceptado el 8 de abril de 2020

\begin{abstract}
Estamos llamados a ser resilientes. Entre guerras, conflictos armados, pandemias y diferencias sociales están que acaban con la humanidad. En el último siglo, estos han dejado tanto impacto, que no somos los mismos luego de haberlos vivido. Rafael Pardo Rueda, economista, profesor universitario e investigador, con una hoja de vida repleta de experiencia en cargos públicos, narra en su libro La historia de las guerras, que estas " [...] no empiezan por casualidad, y ocurren, en general por profundas razones sociales, políticas o económicas, y usualmente tampoco se acaban solas", a lo que agrega, Karl von Clausewitz "la guerra es la continuación de la política por otros medios", y creo que se podrían aplicar los mismos conceptos a las pandemias.

La historia del siglo XX e inicios del XXI es la historia de las guerras y pandemias. Nunca antes se habían librado dos guerras de la magnitud y duración de la Primera y Segunda Guerras Mundiales; además, con tan poco tiempo entre el desarrollo de una y otra.
\end{abstract}

\section{Primera Guerra Mundial}

La mayoría de los países involucrados no eran todavía independientes, sino que formaban parte de los seis imperios o potencias coloniales (Reino Unido, Francia, Rusia, Alema-

Correo electrónico: decheverri@cardioinfantil.org nia, Austria-Hungría, Imperio otomano). En realidad, sólo una decena de países independientes entran en guerra en el verano de 1914 y los otros se van uniendo progresivamente, como Italia en 1915 o Estados Unidos en 1917. Entre todos, suman 600 millones de habitantes, es decir, la mitad de la población mundial por aquel entonces. Sólo consiguen permanecer neutrales durante la contienda bélica, esencialmente América Latina y el norte de Europa.

Entre 1914 y 1919, esta guerra produjo la pérdida de la vida de aproximadamente 30 millones de personas, entre civiles y militares. Además, los heridos graves rusos fueron 4 a 6 millones, los ingleses 3 millones, los franceses 5 millones, los alemanes 6 millones, los italianos 1,6 millones y los serbios 1,7 millones. Los gases de combate, usados por primera vez en 1915, dejaron 20.000 muertos y una huella tremenda en la memoria de la gente por los éxodos masivos de la población, las hambrunas, la guerra civil en Rusia y los conflictos regionales de la posguerra, que pudieron haber causado entre 5 y 10 millones de muertos más, según las estimaciones de varios historiadores.

Al final de la guerra, una pandemia mundial de gripe, la llamada gripe española, dejó decenas de millones de víctimas en Europa agravando el problema de los millones de prisioneros en las cárceles, más de 10 millones de refugiados en toda Europa, millones de viudas y huérfanos, desempleo, recesión económica y un costo de 180.000 millones de dólares a los principales beligerantes; o sea, entre tres y cuatro 
veces el producto interno bruto (PIB) de los países europeos, que acabaron arruinados. A pesar de todo este sufrimiento, la humanidad se recuperó nuevamente.

\section{Segunda Guerra Mundial}

La contabilización de las víctimas de esa guerra ha sido objeto de numerosos estudios y publicaciones, libros y documentales, elevándose hasta más de 100 millones según los cálculos más pesimistas, y de 40 a 45 millones según los más optimistas. Parece que murieron 400.000 soldados norteamericanos, 200.000 polacos, 292.000 franceses y 500.000 yugoslavos. El ejército nazi perdió pocos soldados al inicio de la guerra, tan solo 16.000 . Luego, los nazis perdieron 500.000 militares luchando contra Estados Unidos y el Reino Unido en el frente oeste. Solo en Europa, el ejército alemán perdió 2,8 millones de soldados durante esta guerra. A esta cifra hay que agregarle los soldados alemanes que murieron en el norte de África y militares nazis de los países aliados a la Alemania nacionalsocialista. Los Aliados ganaron la guerra gracias a la Unión Soviética, y ésta sufrió el mayor número de muertes militares: 8.7 millones de soldados.

La Segunda Guerra Mundial cambió la historia de la humanidad. A pesar de todo este sufrimiento, la humanidad se recuperó nuevamente. Trajo consigo muchos cambios alrededor del mundo, ya fueran cambios de pensamiento o en la forma en la que la gente se relacionaba con la tecnología. Este despertar de la sociedad también trajo consigo muchas teorías conspirativas en contra de otros países, y, por tanto, paranoia y miedo entre las personas.

\section{1 de septiembre de 2001}

Los atentados del 11 de septiembre de 2001, también llamados "9/11", "11/9" y "115", fueron una serie de cuatro atentados terroristas suicidas cometidos la mañana de ese día en los Estados Unidos por la red yihadista Al Qaeda, que, mediante el secuestro de aviones comerciales para ser impactados contra diversos objetivos, causaron la muerte de 3.016 personas, incluidos los 19 terroristas, 24 desaparecidos y más de 26.000 heridos. A su vez, se registró la destrucción de todo el complejo de edificios del World Trade Center, más notablemente conocido como Las Torres Gemelas de Nueva York, y graves daños en el edificio del Pentágono, sede del Departamento de Defensa de los Estados Unidos. Según una especulación científica, la exposición a varios productos tóxicos y contaminantes del aire circundante como consecuencia del derrumbe del World Trade Center podría tener efectos negativos en el desarrollo fetal. Este episodio precedió a la guerra de Afganistán y a la adopción por parte del Gobierno estadounidense y sus aliados de la política denominada «guerra contra el terrorismo». Los atentados, que fueron condenados inmediatamente por el Consejo de Seguridad de Naciones Unidas, tuvieron un impacto significativo en los mercados económicos estadounidenses y mundiales. Sin duda, este atentado cambió la historia de la humanidad en la era reciente. A pesar de todo este sufrimiento, Estados Unidos se recuperó nuevamente.

\section{Conflicto armado en Colombia}

Desde 1958 (incluso antes, en el periodo conocido como "La violencia'”) grupos insurgentes y guerrilleros en contra del gobierno han sido protagonistas de innumerables combates, asaltos a bases militares, tomas de cabeceras municipales, masacres, atentados terroristas y actos de violencia sexual en Colombia. Las víctimas son los miles de muertos, lisiados, secuestrados, desplazados, desaparecidos y demás víctimas de distintas formas de violencia por los diferentes actores violentos del conflicto. Gracias a este conflicto, Colombia es uno de los países con más desplazados internos, afectados por el narcotráfico y el terrorismo del mundo. Para el año 2018, el conflicto armado colombiano había dejado 8'708.664 víctimas, según el Registro Único de Víctimas (RUV), de las cuales 2'365.997 eran niños. Las comunidades que fueron golpeadas con mayor dureza por el conflicto fueron las indígenas, afrodescendientes y campesinas. En el 2013 un estudio cifró en 220.000 las muertes causadas por el conflicto desde 1958. Sin embargo, si se suman el resto de personas que han sufrido otros crímenes de guerra, la cifra total supera los 6 millones de víctimas. Dentro de estas categorías se encuentran las personas que fueron desaparecidas, amenazadas, secuestradas, víctimas de algún acto de terrorismo, afectadas por el asesinato de un ser querido, víctimas de minas antipersonales, tortura, reclutamiento forzado de menores de edad y violencia sexual. Este conflicto ha dejado profundas heridas en el pueblo colombiano, que hace que se encuentre en un proceso de paz largo y difícil. Sin duda, este conflicto cambia la historia del país en la era reciente. A pesar de todo este sufrimiento, Colombia viene en una fase de recuperación.

\section{Otras guerras recientes}

Estos conflictos, según la ONU, causan al menos 1.000 muertes violentas al año, conocidos también como "conflictos de baja intensidad"'. Solo para recordar, en los últimos veinte años, es decir, en el siglo XXI, el mundo continúa siendo espectador de la insurgencia islamista en Nigeria, la guerra civil siria, la guerra civil sursudanesa, la intervención militar en Malí, la guerra civil iraquí, la guerra de Libia, la guerra contra el Estado islámico, la guerra civil yemení, la insurgencia en Magreb, la guerra en el noroeste de Pakistán, la guerra en el este de Ucrania, entre muchos otros conflictos.

\section{Pandemia de gripe 1918-1919}

Parece que empiezan a existir pandemias con el surgimiento del capitalismo mercantil, proceso que inaugura el libre intercambio de microbios entre nuevos y viejos mundos. La primera gran mortalidad se debió a una epidemia de "influenza porcina o gripe del cerdo", el acontecimiento histórico-epidemiológico y de la salud pública más importante del Nuevo Mundo, tras la llegada del segundo viaje de Colón. Durante los siglos XVIII, XIX y XX sucedieron veintidós pandemias.

Se estimó que la pandemia ocurrida entre 1918-1919 provocó la muerte de aproximadamente 50 millones de personas en menos de un año, infectó a la tercera parte de la población mundial y mató a casi el $6 \%$ de la misma. Las pandemias 
de 1957 y 1968 fueron menos letales, causaron de 1 a 4 millones de defunciones en grupos de riesgo alto, como niños y ancianos. Recientes investigaciones demuestran la relación entre la Primera Guerra Mundial y la pandemia de gripe de 1918, dada la masiva movilización de jóvenes soldados, animales de transporte, como caballos, y de alimento, como cerdos, patos y gallinas, huéspedes habituales del virus de la gripa. En noviembre de 1918, al final de la guerra, se produjo la segunda oleada de la pandemia y el pico más alto de mortalidad, en plena época de lluvias, en una Europa destruida, hambrienta y asolada por la tuberculosis, campo abonado por el conflicto bélico, sin el cual la rápida difusión no se hubiera presentado.

En las últimas décadas, la pandemia de gripa de 1918 ha suscitado un creciente interés tras la reaparición del $\mathrm{H}_{1} \mathrm{~N}_{1}$ en 2009. Antes del 2005, los estudios sobre las pandemias eran escasos en Asia, África, Europa oriental y América Latina, a excepción de Brasil. A pesar de todo este sufrimiento, la humanidad se recuperó nuevamente.

\section{Pandemia de coronavirus -COVID-19}

El brote de la enfermedad por coronavirus 2019 (COVID-19) en China comenzó en la ciudad de Wuhan en diciembre de 2019. El virus se propagó rápidamente debido a su alta capacidad para la transmisión de persona a persona, el período largo de incubación y las características de infección en individuos asintomáticos. En las primeras etapas del brote, se consideró que la tasa de infección nosocomial podría alcanzar el $41 \%$ sin una intervención rápida. El 20 de enero de 2020, la Comisión Nacional de Salud de China anunció que el COVID-19 había sido incluido en la lista de enfermedades infecciosas de clase B clasificadas por la Ley China para la Prevención y Control de Enfermedades Infecciosas, y debería ser manejado como una enfermedad infecciosa de clase A. De inmediato, se tomaron medidas estrictas de cuarentena en la provincia de Hubei y otras regiones de ese país.

El brote surgió en el invierno y la primavera, estaciones marcadas por una alta incidencia de enfermedades cardiovasculares. Por lo tanto, impactó el tratamiento de pacientes con eventos cardiovasculares, debido a restricciones de cuarentena y sistemas de emergencia públicos sobrecargados, y, adicionalmente, surgieron demoras entre el inicio de los síntomas y la consulta médica. Ante la necesidad de un control epidémico, el personal médico sobrecargado en los servicios de urgencias luchó para proporcionar opciones de diagnóstico y tratamiento oportunas; los pacientes con sospecha o confirmación de COVID-19 fueron tratados adecuadamente de forma conservadora con medicamentos, para evitar y limitar la transmisión nosocomial.

El Doctor Tedros Adhanom, Director de la OMS, el 11 de marzo de 2020, al documentar que el número de casos por coronavirus fuera de China aumentó 13 veces y que el número de países afectados se triplicó en las últimas dos semanas, declaró la pandemia por coronavirus. Por primera vez una pandemia de estas características obligó a todos los países del mundo a tomar medidas urgentes y agresivas para combatir el brote, a pesar de que muchos carecen de recursos y de capacidad instalada y de resolución a este tipo de problemas. El día 22 de marzo de 2020, la Ministra del
Interior de Colombia, la Dra. Alicia Victoria Arango, junto con otros ministros, ordena publicar y cumplir el Decreto número 457 de 2020, por el cual se imparten instrucciones en virtud de la emergencia sanitaria generada por la pandemia del coronavirus COVID-19 y el mantenimiento del orden público, y decreta el aislamiento preventivo obligatorio de todas las personas habitantes de la República de Colombia desde el día 25 de marzo hasta el 13 de abril del 2020.

Analizando lo sucedido en todo el mundo, vemos que la primera ola golpeó a China, la segunda a Corea del Sur, Italia e Irán, y luego, solo por aproximadamente una semana, a Francia, Alemania, España y los Estados Unidos. El comportamiento de esta pandemia hace que casos confirmados, recientemente diagnosticados, se tripliquen cada dos días. Aproximadamente, el $25 \%$ de las muestras de hisopos que se someten a prueba son positivas; entonces, el virus está en todas partes, sabemos que estamos en la fase de crecimiento exponencial de la epidemia. Modelar la pandemia de COVID-19 ha sido un gran desafío. Un análisis reciente a gran escala de China sugiere que el $80 \%$ de los infectados son asintomáticos o tienen síntomas leves, un hallazgo que implica que la demanda de los servicios médicos avanzados, puede aplicarse solo al $20 \%$ del total de los infectados.

De los pacientes infectados con COVID-19, aproximadamente el $15 \%$ tiene una enfermedad grave y el $5 \%$ tiene una enfermedad crítica. La mortalidad general varía de $0.25 \%$ a un máximo de $3.0 \%$. Las tasas de letalidad son mucho más altas para las poblaciones vulnerables, como personas mayores de 80 años (> 14\%) o con afecciones coexistentes (10\% para personas con enfermedad cardiovascular y $7 \%$ para personas con diabetes). En general, el COVID-19 es sustancialmente más mortal que la gripe estacional, que tiene una mortalidad de aproximadamente $0.1 \%$.

\section{Consecuencias directas de la infección viral por COVID-19}

Día tras día, recibimos cada vez más información acerca de los mecanismos potenciales de los efectos agudos de la infección viral a nivel pulmonar y cardiovascular, como los principales sistemas afectados, induciendo una respuesta inflamatoria aguda y la denominada "tormenta por citoquinas", estados de hipercoagulabilidad, estimulación simpática, incremento en las demandas de oxígeno, síndrome de distrés respiratorio y sobreinfección pulmonar temprana, miocarditis aguda y necrosis, y depresión miocárdica, finalmente con las consecuencias de insuficiencia respiratoria, riesgo alto de infarto agudo del miocardio, falla cardiaca aguda y arritmias de alto riesgo.

\section{Consecuencias indirectas de la infección por COVID-19}

Nunca en la historia se había vivido una pandemia en la que, minuto a minuto, se contaran los muertos, las víctimas y los casos positivos. Las recomendaciones de los científicos, los epidemiólogos y los políticos y dirigentes de los países han generado y difundido las medidas básicas de higiene de manos y los confinamientos, aislamientos personales y sociales prolongados, y han producido serios riesgos laborales, que han incrementado de manera dramática el desempleo, 
así como la sensación de limitación en el acceso a los alimentos básicos y de inseguridad, causando una pérdida de confianza entre las mismas comunidades.

En una sociedad moderna hiperconectada, con un dramático incremento en el uso de redes sociales, información inexacta, o aun falsa, el control de la información es más desafiante, con el agravante que, a menudo, la información exagerada o engañosa exacerba las ansiedades ya existentes y deriva en pánico colectivo y brotes sicológicos.

La economía mundial se ve débil y se rinde ante el virus. Esta situación ha venido obligando progresivamente a los gobiernos de la mayoría de países del mundo a dictar medidas de aislamiento de la población, con consecuencias dramáticas sobre sus economías, pues los sistemas productivos quedan paralizados, lo cual incide directamente en la inversión, el desempleo y el consumo. Lo anterior, sumado al nerviosismo, generado por el desconocimiento de la nueva enfermedad, y a la guerra comercial sobre la producción de petróleo (que probablemente comienza a solucionarse) ha causado una fuerte caída de los mercados globales, que ha llevado a los expertos a reducir las cifras de crecimiento estimado para este año, sin que sea posible descartar que podamos enfrentar una recesión económica mundial. Se mezclan la caída del precio del petróleo, la caída de las tasas de interés y el desplome de las bolsas de inversión y de los índices económicos como el FTSE, Dow Jones y el Nikkei, con un gran impacto en los mercados bursátiles y hasta en los fondos de pensiones. Al paso que vamos y si la economía sigue frenada, la crisis, la recesión, el desempleo van a ser también protagonistas, y eso, igualmente, generará millones de muertes que no están siendo tomadas en cuenta. A esta información se aúna la suspensión de los Juegos olímpicos en Japón, la crisis de las ligas de fútbol del mundo y la paralización de todos los espectáculos deportivos y culturales. Además, recibimos noticias poco relevantes de si los deportistas profesionales y políticos se deben bajar los sueldos (más no si estos últimos deben generar mejores políticas anticorrupción). Si bien este panorama preocupa, el aprendizaje que han tenido los gobiernos de las crisis vividas durante los últimos años les ha permitido actuar oportunamente, tomando toda clase de medidas (sanitarias, monetarias y fiscales) para alivianar el peso de esta situación sobre sus países. Para ello, a pesar de enfrentarnos a un escenario nunca antes visto, se considera que una vez se logre controlar la curva de contagios y reactivar los sistemas productivos, podríamos nuevamente ubicarnos en terreno positivo.

\section{¿Volveremos a ser los mismos?}

Los efectos de estar embebidos en las redes sociales, la internet, la comunicación rápida por chats, las reuniones virtuales utilizando cada vez nuevas y mejores plataformas han cambiado la forma de comunicarnos, de hacer negocios locales e internacionales, de educar en colegios y univer- sidades; surge el teletrabajo como una nueva manera de generar ingresos y continuar trabajando para las empresas sin necesidad de desplazarse, exponerse a riesgos, incrementando el tráfico en las calles y aumentando la polución ambiental. Accedemos a la información y a programas culturales a través de la internet, incluso ha cambiado la forma de conseguir alimentos mediante domicilios, y estos cambios han permitido estar más tiempo en el hogar compartiendo con la familia, ha disminuido la contaminación ambiental, se han recuperado los glaciares y la capa de ozono, y han renacido especies animales y vegetales que estaban destinadas a la extinción.

¿Será que esta pandemia también cambió el patrón de las enfermedades? Notamos la dramática reducción de consultas de urgencias y electivas de las principales causas de morbimortalidad, como las cardiovasculares, cáncer, respiratorias y accidentes de tránsito ¿Dónde están el número de muertes por enfermedades cardiovasculares, supuestamente 1 cada 9 segundos en el mundo y 200 muertes al día en Colombia? ¿Será que este freno de la sociedad también reduce la mortalidad por enfermedad coronaria, cáncer, estrés, etc.? Por otra parte, hay estudios que demuestran el aumento en suicidios y enfermedades cardiovasculares asociadas a las crisis.

\section{Conclusión}

La naturaleza, después de pedir a gritos mayor conciencia a la sociedad para generar cambios fundamentales, se está manifestando y nos obliga a cambiar. No debemos ser los mismos, debemos pensar en una sociedad más civilizada, más justa, respetuosa del medio ambiente, equitativa, exigente con el cumplimiento de las normas y más rígida ante la corrupción y la violación de los derechos humanos. La salud global (física y mental) nunca será la misma después del COVID-19, no puede ser. Debemos cambiar y avanzar rápidamente, por nuestra propia seguridad y la de nuestros descendientes, más allá de la retórica de la igualdad y la búsqueda de un sistema más democrático, más multipolar, más interconectado y mejor distribuido.

Resiliencia es un término que deriva del verbo en latín resilio, resilire, que significa "saltar hacia atrás, y rebotar', Se refiere a la capacidad de sobreponerse a momentos críticos y adaptarse luego de experimentar alguna situación inusual e inesperada. También indica volver a la normalidad. La resiliencia es una aptitud que adoptan algunos individuos que se caracterizan por su postura ante la superación de una adversidad y de mucho estrés, con el fin de pensar en un mejor futuro. La humanidad, a pesar de guerras, conflictos y pandemias que han dejado profundas huellas, ha demostrado resiliencia. Se hacen necesarios dirigentes y líderes resilientes, que en medio de estas situaciones adversas particulares, tomen decisiones asertivas y conviertan los momentos difíciles en una oportunidad de cambio hacia el mejoramiento y fortalecimiento de la sociedad. 